\title{
AVALIAÇÃO ERGONÔMICA DO TRABALHO EM ALTURA EM FACHADAS DE ESTRUTURAS VERTICAIS
}

\section{ERGONOMIC ASSESSMENT OF WORK AT HEIGHT FACADES STRUCTURES VERTICAL}

\author{
Juliano Prado Stradioto $^{1}$; Fernando Gonçalves Amaral ${ }^{2}$ \\ ${ }^{1}$ Universidade Federal do Rio Grande do Sul - UFRGS - Porto Alegre - RS - Brasil \\ juliano.stradioto@gmail.com \\ ${ }^{2}$ Universidade Federal do Rio Grande do Sul - UFRGS - Porto Alegre - RS - Brasil \\ amaral@producao.ufrgs.br
}

\begin{abstract}
Resumo
$\mathrm{Na}$ Construção Civil existe um grande número de situações envolvendo risco de vida $e$ consequentemente problemas ergonômicos aos trabalhadores envolvidos, gerando uma variabilidade em todo processo de execução. Dentre todos os riscos conhecidos e estudados no ramo da Construção Predial, os serviços de execução de fachada encontra-se no topo da lista em termos de acidentes de trabalho e desconforto ergonômico a saúde do trabalhador. A NR-18 quando especifica os itens a serem cumpridos pelo PCMAT de cada obra, não enfatiza o planejamento a segurança do trabalho e muito os riscos a saúde que os trabalhadores serão expostos. O desafio em termos ergonômicos para esse tipo de serviço é a área de trabalho estar totalmente organizada, com o uso das ferramentas adequadas, respeitando rigorosamente a norma, identificação dos operadores, a postura correta no levantamento do material e execução do serviço, sobretudo a realização do check list nos equipamentos de trabalho em altura e conferência dos EPIs. A fim de verificar os principais riscos dessa atividade aos trabalhadores envolvidos, foi realizada uma análise através do método de Diagnóstico preliminar Participativo de Risco (Deparis), resultando na confirmação do caráter prejudicial da atividade, pois possui condições que precisam de correção imediata.
\end{abstract}

Palavras chaves: ergonomia; fachada; construção civil; deparis

\section{Introdução}

No ramo da Construção Civil, especificamente na execução de fachadas em obras Prediais, há variabilidade ao longo de todo o processo de execução deste tipo de serviço, podendo ser tanto no produto, quanto ao ambiente externo de trabalho. A fachada de um prédio pode ser executada em diversos materiais, o que resulta em alterações do processo executivo de execução. Com relação ao ambiente de trabalho, por ser externo e móvel, expondo os trabalhadores aos mais variados fatores climáticos, exigindo adaptações constantes aos diferentes materiais que uma fachada pode conter 
como também aos diferentes equipamentos de elevação que uma obra pode usar ao longo da execução.

As etapas que compõem esse tipo de serviço contêm atividades exclusivamente manuais, que exigem grande esforço físico, além do plano de trabalho estar em ângulo com a parede externa da edificação ou estrutura, o que resulta na permanência em posições desconfortáveis por um período longo de tempo, sem contar no risco constante de queda dos trabalhadores.

Para Cruz (1998), a indústria da Construção Civil é considerada atrasada tanto tecnológica quanto gerencialmente, quando comparada a outros setores. No desejo de se modernizar, o subsetor de edificações tem demonstrado grandes avanços através da incorporação de novas tecnologias de processo às suas atividades tradicionais. Porém, o gerenciamento da segurança e saúde ocupacional gera grandes problemas, principalmente devido à dificuldade da gerência em utilizar abordagens mais modernas na concepção de ferramentas de apoio a gestão. Além da inexistência de suporte teórico dirigido ao setor e a existência de uma cultura de negação do risco amplamente difundida entre o pessoal.

Espinoza (2002) também afirma que a indústria da construção civil, em especial o subsetor de edificações, é frequentemente citada como exemplo de setor atrasado, com baixos índices de produtividade e elevados percentuais de desperdícios de recursos, apresentando, em geral, desempenho inferior à indústria da transformação. A mão-de-obra da construção é, com frequência, vista como responsável por este quadro de ineficiências, sendo comum rotular os operários de displicentes ou incapazes. Entretanto, os operários, não são os únicos responsáveis.

Assim, como qualquer atividade do setor privado, a construção civil visa fundamentalmente o lucro para a suas empresas e, muitas vezes, a forma escolhida para obter maiores lucros se dá através da redução irrestrita dos custos, sendo um deles o da segurança no trabalho. Como alguns profissionais do setor não percebem o impacto da segurança do trabalho na produtividade da empresa, com frequência ela é deixada para um segundo plano (ROCHA, 2000).

Para o Sindicato das Indústrias da Construção Civil do Estado do Rio Grande do Sul (1998), a grande incidência de acidentes de trabalho na construção geralmente é creditada às características extremamente dinâmicas do setor:grande reposição da mão-de-obra; baixo nível de especialização e características próprias da atividade,sempre diferente a cada dia.

Um dos tipos de acidente de trabalho que ocorre com os trabalhadores da Construção Civil, e que também possui consequências graves, é o trabalho com andaimes. A Delegacia Regional do Trabalho e Emprego no Estado do Rio Grande do Sul (DRTE/RS) constata que este tipo de agravo à saúde ocupacional surge, principalmente, nas pequenas e médias empresas e nos casos de trabalho informal. O motivo apontado é o total descumprimento da legislação existente na área de promoção de saúde e prevenção de acidentes de trabalho, afirmando que as condições estabelecidas pela NR- 
18, embora já tenham vários anos de existência, não são aplicadas por todos os empregadores deste tipo de atividade (SINDICATO DA INDÚSTRIA DA CONSTRUÇÃO CIVIL NO ESTADO DO RIO GRANDE DO SUL, 1998).

Outro fator importante para a implantação de um sistema de prevenção de acidentes de trabalho e de soluções ergonômicas para os trabalhadores da Construção Civil é o custo, pois segundo Araújo (2002), existe, de um lado, o PCMAT que é obrigatório para as empresas com vinte trabalhadores ou mais e, de outro, as empresas que são obrigadas a cumprir esta disposição da NR18, mas desconhecem os custos provenientes de sua implantação. Entende-se como implantação do PCMAT a introdução de todos os itens que compõem o referido Programa na obra, e por custos os gastos financeiros provenientes dessas medidas.

Durante todo o processo os colaboradores são submetidos a uma gama de constrangimentos, tais como as diversas condições climáticas, o ruído, a insegurança - devido ao trabalho em altura durante praticamente todo o expediente de trabalho -, a pressão pela produtividade. Apesar destas situações, buscou-se através da analise ergonômica do trabalho e utilização do método de Diagnóstico preliminar Participativo de Risco (Deparis) a identificação dos principais tipos de acidentes de trabalho e a identificação das principais causas, assim como a identificação dos danos à saúde do trabalhador vinculado a este tipo de serviço, sugerindo melhorias ao processo.

A empresa na qual este trabalho foi desenvolvido, tenta na melhor maneira possível cumprir todas as exigências vigentes para o trabalho em altura em fachadas, sendo assim, a análise ergonômica do trabalho pôde focar na avaliação dos trabalhadores deste tipo de serviço, portanto, o objetivo deste estudo é a identificação dos constrangimentos posturais e de saúde em geral, assim como a prevenção para o trabalho em altura, abordando também o custo para as prevenções necessárias para o trabalho em altura, sob um foco ergonômico.

\subsection{Riscos de Acidentes}

Os riscos em que os trabalhadores estão expostos, também podemos citar as pessoas em geral, podem ser divididos em duas categorias: gerais ou profissionais, os primeiros são geralmente encontrados em casa, ou mesmo durante as férias, por exemplo nas estatísticas de acidentes de trânsito, já os riscos profissionais são encontrados no exercício de uma profissão. Esses riscos dependem de mais de um fator: do homem, do lugar de trabalho e do ambiente. Estes riscos são conhecidos e foram avaliados e classificados, mas é impossível determinar a hora e local onde um acidente poderá acontecer (OrganismeProfessionnel de PréventionduBâtiment et desTravaux Publiques, 1975). Segundo esta Organização, o acidente pode ser definido como sendo um deslocamento do homem em direção ao objeto, ou inversamente, acarretando um contato, para evitá-lo, é preciso interpor um obstáculo, podem-se definir três tipos de acidentes: 
- De trabalho: é o evento material, repentino, violento, exterior ao homem, que se produz durante o tempo e no local de trabalho, devido ao trabalho ou na oportunidade do mesmo, provocando lesões corporais ou a morte. Considera-se acidente material ou incidente quando não houver ferimento de pessoa;

- A caminho do local de trabalho:ocorre no trajeto normal ou habitual, sem desvio ou atraso no interesse da vítima. Deve ser localizado no tempo e no espaço. Este tipo de acidente também é conhecido como acidente de trajeto.

- Doença profissional: é o resultado de um contato direto com o trabalho realizado e ocorrido na oportunidade do mesmo. Trata-se de alteração mais ou menos lenta, consequência de contato contínuo ou intermitente.

O conhecimento deficiente por parte da maioria das empresas, especialmente as de médio e pequeno porte, sobre o tema da Segurança do Trabalho e Ergonomia em canteiros de obras e suas repercussões, e sobre a realidade interna de riscos, faz com que elas desconsiderem a necessidade de adotar medidas de proteção ou, até mesmo, as estimula a resistir, ativa ou passivamente, à adoção de práticas de segurança de trabalho adequadas. Isso gera um atrito crescente entre os agentes públicos de fiscalização e as empresas (ROCHA, 2011), e entre empresas e sindicatos de trabalhadores levando a paralisações de obras e demanda de variadas ações na resolução dos problemas.

Uma pesquisa sobre abordagens de temas relacionados à Ergonomia e ST nos eventos da ANTAC - ASSOCIAÇÃO NACIONAL DE TECNOLOGIA DO AMBIENTE CONSTRUÍDO, de 1993 a 2005, reconheceu que, apesar da quantidade e qualidade dos assuntos encontrados, é possível efetuar desdobramentos para trabalhos futuros, tais como os aspectos organizacionais relacionados à urgência de prazos e quantidades exigidas da produção que afetam o estado de espírito do trabalhador e sua produtividade (KRÜGER e COELHO, 2006), consequentemente, comprometendo a segurança do trabalho nas obras.

Com os dados coletados pelo INSS sobre os registros dos acidentes de trabalho, conforme a tabela 01, segundo o setor de atividade econômica, em o Brasil entre os anos de 2011 e 2013, comparando o número total de acidentes registrados no setor da construção com os demais da indústria produtiva, nota-se que o setor da Construção Civil sozinho representou em 2013 cerca de $6,46 \%$ de todos os acidentes de trabalho comunicados. 
Tabela 01 - Resumo dos acidentes de trabalho registrados, por motivo, segundo o setor de Atividade Econômica no Brasil entre os anos de 2011 e 2013.

\begin{tabular}{|c|c|c|c|c|c|c|c|}
\hline \multirow{3}{*}{$\begin{array}{c}\text { SETOR DE } \\
\text { ATIVIDADE } \\
\text { ECONÔMICA }\end{array}$} & \multirow{3}{*}{ Anos } & \multicolumn{6}{|c|}{ QUANTIDADE DE ACIDENTES DO TRABALHO REGISTRADOS } \\
\hline & & \multirow{2}{*}{ Total } & \multicolumn{3}{|c|}{ Motivo } & \multirow{2}{*}{$\begin{array}{c}\text { Total de } \\
\text { acidente da } \\
\text { Construção } \\
\text { X Total } \\
\text { geral de } \\
\text { empresas }\end{array}$} & \multirow{2}{*}{$\begin{array}{c}\text { Total de } \\
\text { acidente da } \\
\text { Construção } \\
\text { X Total } \\
\text { geral de } \\
\text { indústrias }\end{array}$} \\
\hline & & & Típico & Trajeto & $\begin{array}{l}\text { Doença } \\
\text { do } \\
\text { trabalho }\end{array}$ & & \\
\hline TOTAL & 2011 & 340.251 & 282.965 & 38.799 & 18.487 & & \\
\hline GERAL DE & 2012 & 393.071 & 323.879 & 46.881 & 22.311 & & \\
\hline EMPRESAS & 2013 & 390.180 & 319.093 & 49.069 & 21.208 & & \\
\hline & 2011 & 160.020 & 138.934 & 12.578 & 8.508 & & \\
\hline Indústrias & 2012 & 177.833 & 153.444 & 14.474 & 9.915 & & \\
\hline & 2013 & 140.973 & 120.551 & 12.605 & 7.817 & & \\
\hline & 2011 & 3.159 & 2.776 & 183 & 200 & & \\
\hline Extrativa & 2012 & 3.103 & 2.786 & 147 & 170 & & \\
\hline & 2013 & 2.260 & 2.018 & 119 & 123 & & \\
\hline & 2011 & 25.466 & 22.557 & 2.154 & 735 & $7,48 \%$ & $15,91 \%$ \\
\hline Construçao & 2012 & 28.484 & 25.029 & 2.532 & 923 & $8,37 \%$ & $16,02 \%$ \\
\hline & 2013 & 21.972 & 19.093 & 2.187 & 692 & $6,46 \%$ & $15,59 \%$ \\
\hline & 2011 & 8.365 & 6.950 & 1.124 & 291 & & \\
\hline Indústria & 2012 & 9.550 & 8.010 & 1.216 & 324 & & \\
\hline & 2013 & 6.610 & 5.506 & 914 & 201 & & \\
\hline & 2011 & 124.532 & 107.324 & 10.101 & 7.384 & & \\
\hline Transformação & 2012 & 137.528 & 118.323 & 11.345 & 9.423 & & \\
\hline & 2013 & 111.230 & 94.567 & 9.435 & 7.231 & & \\
\hline
\end{tabular}

Consultando a base de dados do Ministério da Previdência Privada (MPS, 2014), quadro 01, nos mostra o número de acidentes de trabalho, na construção Predial, por agrupamento de CID, referente a quedas, exposição a forças mecânicas, exposição à corrente elétrica, à radiação e as temperaturas e pressões extremas do ambiente e outros riscos acidentais à respiração, comparando os números totais do país e do estado do Rio Grande do Sul, entre os anos de 2010 e 2013. 
Quadro 01: Número de acidentes, na execução de edifício, por agrupamento CID, no País e RS

\begin{tabular}{|c|c|c|c|c|c|c|c|c|}
\hline \multirow{2}{*}{ Agrupamento CID } & \multicolumn{2}{|c|}{2010} & \multicolumn{2}{|c|}{2011} & \multicolumn{2}{|c|}{2012} & \multicolumn{2}{|c|}{2013} \\
\hline & $\mathrm{BR}$ & $\mathrm{RS}$ & $\mathrm{BR}$ & $\mathrm{RS}$ & $\mathrm{BR}$ & $\mathrm{RS}$ & $\mathrm{BR}$ & $\mathrm{RS}$ \\
\hline $\begin{array}{c}\text { (W00-W19) } \\
\text { Quedas }\end{array}$ & 754 & 44 & 731 & 13 & 834 & 21 & 956 & 11 \\
\hline $\begin{array}{c}\text { (W20-W49) } \\
\text { Exposição a forças } \\
\text { mecânicas } \\
\text { inanimadas }\end{array}$ & 401 & 8 & 517 & 11 & 567 & 19 & 611 & 17 \\
\hline $\begin{array}{c}\text { (W85-W99) } \\
\text { Exposição à } \\
\text { corrente elétrica, à } \\
\text { radiação e às } \\
\text { temperaturas e } \\
\text { pressões extremas } \\
\text { do ambiente }\end{array}$ & 256 & 11 & 276 & 5 & 287 & 13 & 356 & 7 \\
\hline $\begin{array}{l}\text { (W75-W84) } \\
\text { Outros riscos } \\
\text { acidentais à } \\
\text { respiração }\end{array}$ & 17 & 3 & 22 & 5 & 31 & 17 & 17 & 11 \\
\hline Total CID & 1428 & 66 & 1546 & 34 & 1719 & 70 & 1940 & 46 \\
\hline
\end{tabular}

Fonte: MPS, 2014

\subsection{Realidade dos Acidentes de Trabalho em Altura na Construção Predial}

Os acidentes mais frequentes são aqueles associados à indústria da Construção Civil, especialmente aqueles envolvendo quedas de trabalhadores como pedreiros, carpinteiros e serventes, que estavam executando serviços em escadas, telhados, andaimes e fachadas.

A Construção Civil no Brasil sempre será um bom indicador do crescimento econômico do país, na década de 70 a média do Produto Interno Bruto (PIB) atingiu 8,8\% (IBGE, 2014), porém em conjunto com esse crescimento, ocorre um forte aumento na quantidade de acidentes de trabalho, sobre tudo os ligados a queda em altura, pelo mais diverso motivos.

Quedas são apontadas como sendo responsáveis pelo maior número de acidentes fatais, juntamente com os acidentes causados por choque elétrico e soterramento (REVISTA CORBERTURA, 2010; MANGAS, 2003), associadas às diversas atividades na construção de prédios, tais como: aplicação de revestimentos, pintura, manutenção e conservação de fachadas de edifícios (PAMPALON, 2004), além de montagens de formas, concretagem e desforma na fase de estruturas desenvolvidas por carpinteiros, pedreiros e ferreiros (VÉRAS, 2004).No quadro 02sãoidentificados os tipos de acidentes mais frequentes levando em consideração à natureza do 
acidente e o agente da lesão, concluindo que o acidente envolvendo queda em serviço em altura fica em $1^{\circ}$ lugar.

O estudo de Costella et al. (1998) concluiu que os avanços tecnológicos, quando associados ao bem estar e segurança dos trabalhadores diminuem e muito os acidente em canteiros de obras, e por consequência o custo de produção, levando-se a conclusão que o valor investido em segurança do trabalho e bem estar dos trabalhadores são recompensadores a empresa.

\section{Metodologia de Pesquisa}

Nesse capítulo, descreve-se o método utilizado na pesquisa de campo para a criação de um modelo de análise e controle das práticas de segurança junto aos trabalhadores e canteiros de obras em edificações verticais nos serviços externos de fachadas.

Quadro 02: Grupos de acidentes mais frequentes em relação à natureza do acidente

\begin{tabular}{|c|c|c|c|c|}
\hline $\begin{array}{l}\text { Natureza do } \\
\text { Acidente }\end{array}$ & Agente da lesão & Quantidade & $\%$ & $\%$ Acumulada \\
\hline $\begin{array}{c}\text { Queda com } \\
\text { diferença de nível }\end{array}$ & Andaime ou similar & 205 & 7,2 & 7,2 \\
\hline Impacto sofrido & Madeira (peça solta) & 143 & 5 & 12,2 \\
\hline Impacto contra & Serras em geral & 142 & 5 & 17,2 \\
\hline $\begin{array}{c}\text { Queda com } \\
\text { diferença de nível }\end{array}$ & Escada & 135 & 4,8 & 22 \\
\hline Impacto Sofrido & $\begin{array}{c}\text { Ferramenta sem força } \\
\text { motriz }\end{array}$ & 119 & 4,2 & 26,2 \\
\hline Impacto Sofrido & Peça metálica ou vergalhão & 107 & 3,8 & 30 \\
\hline Impacto contra & Prego & 96 & 3,4 & 33,4 \\
\hline Impacto Sofrido & $\begin{array}{c}\text { Forma de madeira ou } \\
\text { metálica }\end{array}$ & 91 & 3,2 & 36,6 \\
\hline $\begin{array}{l}\text { Exposição ao } \\
\text { ruído }\end{array}$ & Ruído & 72 & 2,5 & 39,1 \\
\hline $\begin{array}{c}\text { Esforços } \\
\text { excessivos ou } \\
\text { inadequados }\end{array}$ & $\begin{array}{c}\text { Concreto, cimento ou peça } \\
\text { de concreto }\end{array}$ & 67 & 2,4 & 41,5 \\
\hline $\begin{array}{c}\text { Queda com } \\
\text { diferença de nível }\end{array}$ & Vão livres & 65 & 2,3 & 43,8 \\
\hline Impacto Sofrido & Máquinas ou equipamentos & 64 & 2,3 & 46,1 \\
\hline Impacto Sofrido & Tijolo ou similares & 62 & 2,2 & 48,3 \\
\hline $\begin{array}{c}\text { Prensa ou } \\
\text { aprisionamento }\end{array}$ & Máquinas ou equipamentos & 62 & 2,2 & 50,5 \\
\hline
\end{tabular}




\begin{tabular}{|c|c|c|c|c|}
\hline Impacto contra & Peça metálica ou vergalhão & 55 & 1,9 & 52,4 \\
\hline \multicolumn{2}{|c|}{ Outros tipos de Acidentes } & 1354 & 47,7 & 100 \\
\hline
\end{tabular}

Fonte: COSTELLA et al., 1998

\subsection{Metodologia Aplicada}

A pesquisa foi realizada com dados coletados por meio de pesquisa de campo em uma obra vertical de pequeno porte e questionários e check lists junto a Engenheiros Civis e Mestre de Obras.

Marconi e Lakatos (2002) entendem os objetivos da pesquisa de campo como a busca de informações e/ou conhecimento na obtenção de respostas acerca de um problema, ou a comprovação de uma hipótese, visando descobrir novos fenômenos ou as relações entre esses fenômenos. Para isso, é necessário observar os fatos e fenômenos tal como ocorrem na realidade. Daí, a necessidade da visita in loco, de coletar dados referentes a eles e do registro das variáveis que se pressupõem para análise (OLIVEIRA, 1997; MARCONI E LAKATOS, 2002).

A metodologia foi desenvolvida em três etapas, a $1^{\circ}$ etapa refere-se à análise da situação atual do canteiro em conjunto com a análise preliminar do projeto Arquitetônico da obra contemplando o trabalho em altura na fachada externa, a $2^{\circ}$ etapa diz respeito à aplicação de checklists referentes aos EPCs, EPIs e equipamentos utilizados para realização de serviços na fachada externa e a $3^{\circ}$ etapa refere-se a aplicação do questionário através do método de Diagnóstico preliminar Participativo de Risco (Deparis) junto a um grupo de Engenheiros Civis e Mestre de obras, com o objetivo de mostrar as diferentes opiniões de dois grupos distintos de profissionais, isto é, não somente pelas suas funções diferenciadas mas também pelas suas formações distintas.

\subsection{Serviços em altura na execução em Fachadas}

Considera-se trabalho em altura toda a atividade executada acima de 2,00 m (dois metros) do nível inferior, onde haja risco de queda, adotou-se esta altura como referência por ser a altura de desnível consagrada em várias normas, inclusive internacionais, facilitando a compreensão, eliminando dúvidas de interpretação da Norma e as medidas de proteção que deverão ser implantadas (NR-35)

Os serviços em altura, mais especificamente em fachadas em prédios em construção, pode ser realizados pelas seguintes etapas: chapisco, emboço, reboco, revestimento em placas ou em pastilhas ou pintura externa.

Para a execução destes serviços é necessário uma estrutura, andaime fachadeiro ou balancim, para realizá-los com segurança e conforto para os trabalhadores, também é necessário que se proteja os níveis inferiores, bandejas primária e secundária, com o objetivo de evitar quedas acidentais de objetos nas pessoas no solo ou acidentes materiais. 


\subsection{Métodos Sobane e de Deparis}

A Estratégia SOBANE de Gestão de Riscos tem como objetivo abordar progressivamente as situações de trabalho em pequenas e também em grandes empresas, de coordenar a colaboração entre trabalhadores, chefias, médicos do trabalho, prevencionistas, e levando a realização de uma prevenção mais rápida, mais eficaz e menos custosa.

A estratégia descreve os seguintes quatros níveis:

- Diagnóstico preliminar: os fatores de riscos são detectados e as soluções evidentes são colocadas em práticas;

- Observação: onde os problemas restantes (que não puderem ser resolvidos) são aprofundados, para cada fator de risco separadamente, e as causas e as soluções são discutidas de maneira detalhada;

- Análise: onde e quando necessário, se recorre a um prevencionista para realizar as (quantificações) medições indispensáveis e desenvolver soluções específicas;

- Perícia: em casos raros onde um especialista se torna indispensável para estudar e resolver um problema específico(Malchaire, 2003).

A estratégia SOBANE (Screening, Observation, Analysis, Expertise) obedece ao esquema da figura 01:

Figura 01 - Gráfico de Complexidade versus Situações de trabalho

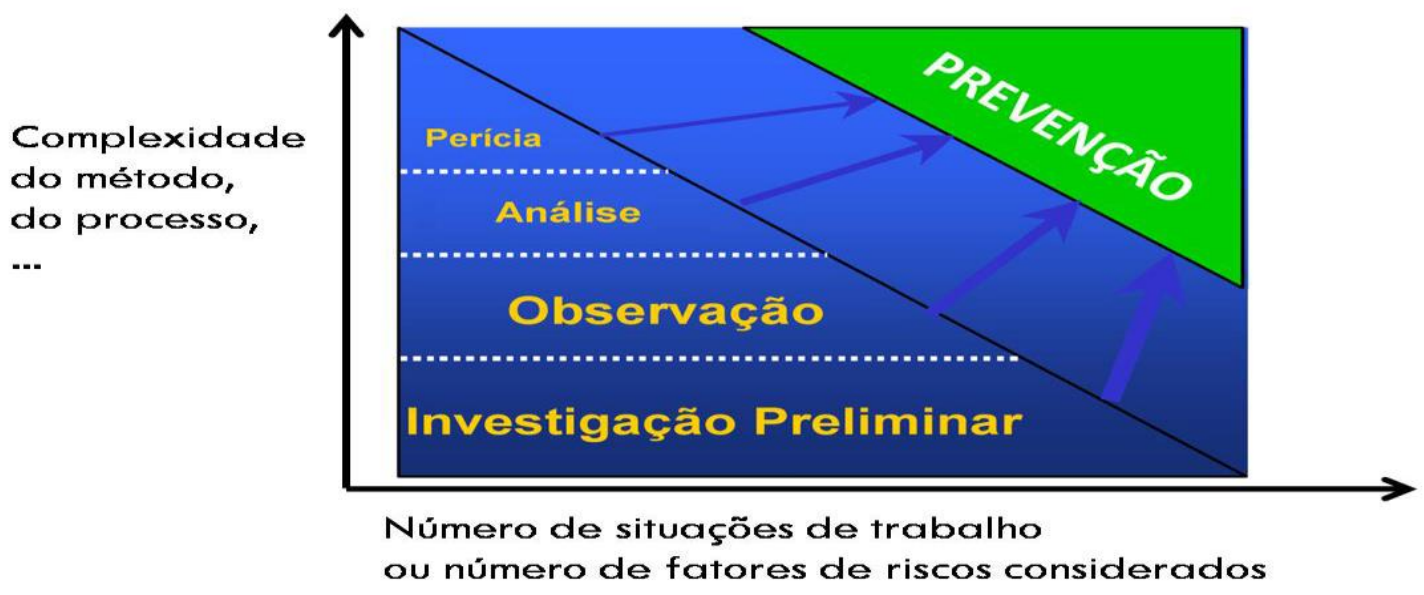

Fonte: Malchaire, 2003

O método Deparis é apresentado sob a forma de 18 rubricas, onde são abordadas 18 diferentes situações de trabalho, nesse artigo serão abordadas as seguintes rubricas:

a) Os locais de trabalho;

b) Os riscos de acidentes;

c) O trabalho repetitivo;

d) Os manuseios (levantamento) de carga; 
O método propõe para cada rubrica uma breve descrição da situação desejada e uma lista de aspectos que devem ser controlados, conforme a figura 02 .

Figura 02: Exemplo de descrições de rubricas

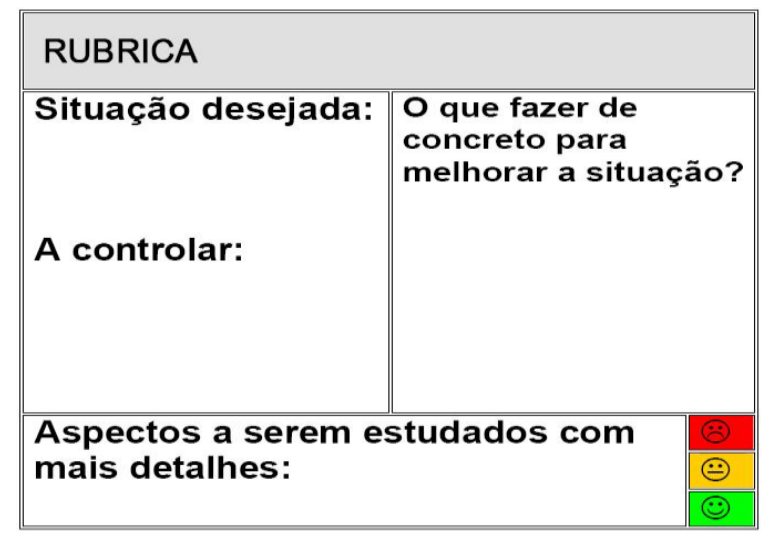

Fonte: Malchaire, 2003

\section{Análise do Canteiro de Obra}

A obra visitada para aplicação dos ckecklists e questionário Deparis, acompanhado pelo responsável técnico da obra, é uma obra localizada na cidade de Santa Maria/RS, executada por uma empresa incorporadora e construtora denominado neste artigo de Construtora SM. Essa é uma obra de porte médio, este empreendimento possui duas torres, dez pavimentos, e dois pavimentos de garagens.

O canteiro de obra, não esquecendo que a obra é de médio porte, é um canteiro de tamanho razoável, porém contempla todas as áreas necessárias exigidas pela NR - 18 como vestiário, banheiros e refeitório, contendo também central de carpintaria, depósitos de materiais e equipamentos, todas essas estruturas respeitando o número de trabalhadores e espaços físicos mínimos exigidos.

Após discussão e análise do projeto Arquitetônico da obra, ficaram estabelecidos os seguintes serviços para execução da Fachada: chapisco, emboço, reboco e pintura externa com duas demãos.

Para execução dos serviços descritos é necessário criar ou utilizar uma estrutura para realizalos com segurança. Da mesma forma é necessário que se proteja o nível inferior de trabalho para que objetos em queda acidental não atinjam pessoas no solo ou causem danos materiais, sendo assim para essa obra a opção escolhida foi o andaime suspenso (balancim) e também o uso de bandejas de proteção, exigidas pela NR -18 .

\subsection{Aplicações de Check Lists e Resultados}


Conforme mencionado anteriormente, o $2^{\circ}$ passo diz respeito à aplicação de três check lists, elaborados para a verificação dos EPCs, EPIs e do equipamento usado para execução dos serviços de reboco externo e pintura externa da obra, os mesmos foram aplicados no responsável técnico da obra acompanhado do mestre de obra.

Primeiramente foi aplicado o check list que diz respeito aos EPCs (Equipamento de Proteção Coletiva), que é obrigação da empresa responsável pela obra oferecer aos seus trabalhadores esse tipo de equipamentos. Esse check list foi elaborado seguindo as orientações da NR - 18, e tem o seu início abordando informações gerais da obra seguidas pelas informações do sistema construtivo escolhido e dados sobre acidentes anteriores, caso tenha acontecido algum, e após esses questionamentos, o questionário vai direto as informações referentes aos EPCs utilizados na obra para prevenção de quedas no trabalho em altura na fachada.

Por se tratar de uma obra de médio porte, alémde ter um orçamento reduzido, que é caso da maioria das empresas do ramo da Construção Civil, a empresa ofereceu em seu canteiro todos os equipamentos básicos para prevenção de quedas, além de manter um canteiro organizado e limpo, tanto no serviço de execução de alvenaria de vedação quanto concretagem, os EPCs usados são os seguintes: sistema de guarda-corpo, linha de vida e bandejas.

Com respeito aos serviços nas Fachadas, à opção escolhida foi o andaime suspenso e a cadeira suspensa para o serviço no poço e áreas pequenas da fachada, a empresa escolheu a locação desses equipamentos, por questão de custo, e conseguiu fechar um contrato com manutenção mensal nesses equipamentos, reduzindo assim consideravelmente o risco de quedas e acidentes.

Claro que a análise poderia ser mais criteriosa, mas por questão de custo e por ser uma empresa familiar, onde o proprietário é o responsável técnico a acompanha a obra diariamente, a empresa deixa de investir em soluções mais modernas, porém mais cara, o que melhoraria as condições de segurança da obra, mas mesmo com orçamento justo a empresa oferece os EPCs necessários para a segurança de todos.

Com relação ao check list de EPIs, Equipamentos de Proteção Individual, a empresa possui um grande zelo com seus funcionários, entregou todos os equipamentos necessários para execução do serviço, mantendo assim a integridade e saúde das pessoas envolvidas.

Finalizando com o Check list do Equipamento (balancim)os principais itens conferidos pelo responsável técnico da obra e da empresa que fornece o equipamento estavam corretos no dia da visita à obra, tinha alguns tubos com ferrugem, algumas placas do piso já desgastadas e alguns itens do travamento precisando de trocas, porém como o contrato prevê visita mensal, esses problemas iriam ser resolvidos na próxima visita, não gerando nenhum risco para o prosseguimento do trabalho. 


\subsection{Aplicação e Resultados do Método de Deparis}

A estratégia SOBANE, tem como princípio a diminuição ou se possível à eliminação dos riscos por complexidade da tarefa, do método ou da demanda. O método para intervenção é composto por quatro níveis: pré-diagnóstico, observação, análise e avaliação.

Trata-se de uma estratégia, neste sentido faz-se necessário a intervenção de ferramentas, dos métodos, dos meios cada vez mais especializados e progressivamente das necessidades. A cada nível, soluções de melhoria das condições de trabalho são procuradas. O recurso ao nível seguinte é necessário apenas se, apesar das melhorias trazidas, a situação de trabalho permanece inaceitável (Malchaire, 2003)

O nível a ser utilizado é o 1 (quadro 03), ou seja, o nível de pré-diagnóstico, onde será aplicado a Lista de Verificação DEPARIS aos funcionários da frente de produção. Cada uma das rubricas utilizadas aborda um tema, onde questões relativas ao mesmo são discutidas com Engenheiros e Mestres de Obra. Foram utilizadasas rubricas 3, 4, 7 e 8, as rubricas utilizadas são referentes à: locais de trabalho, riscos de acidentes, trabalho repetitivo e manuseio (levantamento) de carga respectivamente.

Quadro 03 - Características dos quatro níveis da estratégia SOBANE

\begin{tabular}{|c|c|c|c|c|}
\hline & $\begin{array}{c}\text { Nível1 } \\
\text { Pré-diagnóstico }\end{array}$ & $\begin{array}{c}\text { Nível } 2 \\
\text { Observação }\end{array}$ & $\begin{array}{l}\text { Nível } 3 \\
\text { Análise }\end{array}$ & $\begin{array}{c}\text { Nível } 4 \\
\text { Avaliação }\end{array}$ \\
\hline Quando? & $\begin{array}{l}\text { Sempre em todas } \\
\text { as situações }\end{array}$ & $\begin{array}{l}\text { Situações sem } \\
\text { resolução no } \\
\text { nível } 1\end{array}$ & Casos difíceis & $\begin{array}{c}\text { Casos } \\
\text { complexos }\end{array}$ \\
\hline Como? & $\begin{array}{l}\text { Observações } \\
\text { simples }\end{array}$ & $\begin{array}{l}\text { Observações } \\
\text { qualitativas }\end{array}$ & $\begin{array}{l}\text { Observações } \\
\text { quantitativas }\end{array}$ & $\begin{array}{c}\text { Medições } \\
\text { especializadas }\end{array}$ \\
\hline Custo? & BAIXO & BAIXO & MÉDIO & ALTO \\
\hline Tempo? & 10 minutos & 2 horas & 2 dias & 2 semanas \\
\hline Por quem? & $\begin{array}{l}\text { Pessoas da } \\
\text { empresa }\end{array}$ & $\begin{array}{l}\text { Pessoas da } \\
\text { empresa }\end{array}$ & $\begin{array}{c}\text { Pessoas da } \\
\text { empresa + } \\
\text { conselheiros } \\
\text { em prevenção }\end{array}$ & $\begin{array}{c}\text { Pessoas da } \\
\text { empresa }+ \\
\text { conselheiros em } \\
\text { prevenção } \\
\text { +peritos }\end{array}$ \\
\hline $\begin{array}{l}\text { Conhecimento/Situação } \\
\text { de trabalho }\end{array}$ & Muito elevado & Alto & Médio & Fraco \\
\hline Segurança/saúde & Fraco & Médio & Alto & Especializado \\
\hline
\end{tabular}

Fonte: adaptado de Malchaire, 2003 
Os questionários com a metodologia Deparis foram aplicados em dois grupos de profissionais, o $1^{\circ}$ grupo composto por três Engenheiros Civis, com experiência em execução de obras verticais de no mínimo 05 anos, com uma média de idade de 29 anos $( \pm 2)$ e o $2^{\circ}$ grupo composto por Mestres de obras com uma longa experiência em obras prediais e com média de idade de $47 \operatorname{anos}( \pm 2,3)$.

O objetivo destes questionários é obter um leque de informações com profissionais de formações distintas e experiência variada nas mais diversas situações que podem ocorrer na execução do trabalho em altura em fachadas externas.

O serviço abordado especificamentefoi o serviço em altura de reboco externo em fachadas, a realização deste engloba três operações básicas: preparação da massa, execução do chapisco e aplicação da argamassa (Figura 03).

\section{Figura 03 - execução de reboco externo com sistema de projeção}

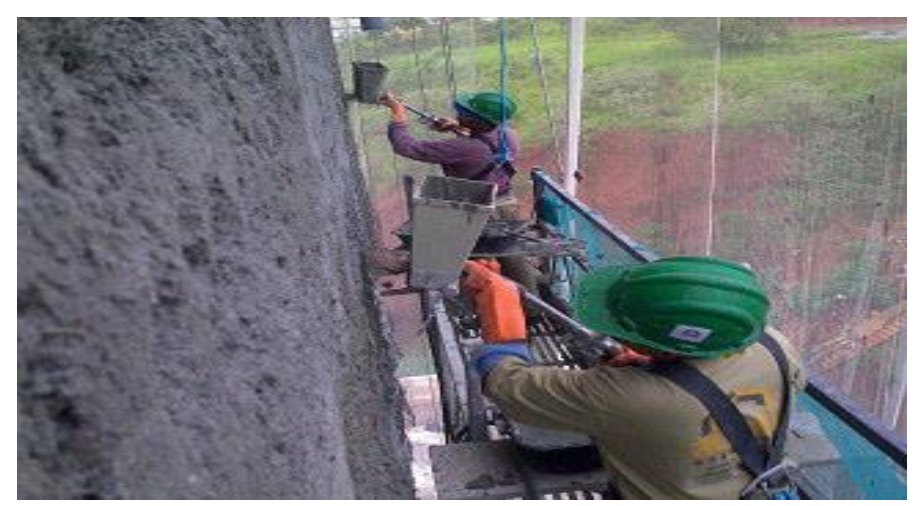

Fonte: Pesquisa de Campo (2015)

Para realização do serviço especificado deste trabalho, há uma série de limitações do ser humano que precisam respeitadas, algumas recomendações ergonômicas são descritas no quadro 04: 
Quadro 04 - Prescrição ergonômica do trabalho a ser realizado

\begin{tabular}{|c|c|}
\hline & $\begin{array}{l}\text { Deve-se respeitar a carga máxima de } 23 \mathrm{Kg} \text {, em } \\
\text { condições ideais de manipulação, recomendado } \\
\text { pela NIOSH. }\end{array}$ \\
\hline $\begin{array}{l}\text { Manipulação Manual de Carga (MMC) segundo } \\
\text { NIOSH (NationalInstitute for }\end{array}$ & $\begin{array}{l}\text { O material a ser manipulado deve estar na altura } \\
\text { entre o joelho e cintura do operador sendo quanto } \\
\text { mais próximo da cintura melhor. O objeto deve } \\
\text { estar a uma distância de no máximo } 40 \mathrm{~cm} \text { do } \\
\text { corpo, sendo } 25 \mathrm{~cm} \text { o ideal. }\end{array}$ \\
\hline OcupationalSafetyand Health) & $\begin{array}{l}\text { Respeitar o limite de dois levantamentos a cada } \\
\text { 5min, quando realizados com a carga máxima. }\end{array}$ \\
\hline & $\begin{array}{l}\text { Evitar levantar cargas em posturas com torção do } \\
\text { tronco, hiperextenção do mesmo bem como com } \\
\text { inclinações laterais. Evitar elevar cargas acima da } \\
\text { altura dos ombros e transportar cargas com um só } \\
\text { braço. }\end{array}$ \\
\hline \multirow{6}{*}{ Postura de trabalho } & $\begin{array}{c}\text { Evitar elevar os braços acima de } 20^{\circ} \text { em relação ao } \\
\text { tronco e abdução dos mesmos. Evitar elevar os } \\
\text { braços acima da linha dos ombros. }\end{array}$ \\
\hline & $\begin{array}{l}\text { Evitar movimentos com amplitude acima de } 15^{\circ} \\
\text { ou repetitivos do punho: extensão, flexão e rotação } \\
\text { bem como desvio ulnar e radial. }\end{array}$ \\
\hline & $\begin{array}{c}\text { Evitar movimentos de inclinação e rotação do } \\
\text { pescoço, bem como flexões e hiperextensões } \\
\text { acima de } 15^{\circ} .\end{array}$ \\
\hline & $\begin{array}{l}\text { Deve-se evitar a flexão do tronco acima de } 20^{\circ} \text { em } \\
\text { relação ao mesmo, bem como rotação e inclinação } \\
\text { lateral do mesmo. }\end{array}$ \\
\hline & $\begin{array}{l}\text { Permanecer com pés e pernas apoiados no chão } \\
\text { com distribuição igual de carga. }\end{array}$ \\
\hline & $\begin{array}{c}\text { Procurar manter o ângulo do antebraço o mais } \\
\text { próximo de } 90^{\circ} \text {, bem como evitar cruzar os braços } \\
\text { da linha sagital ou afasta-los do tronco. }\end{array}$ \\
\hline Repetitividade e Postura Estática & $\begin{array}{c}\text { Evitar realizar movimentos iguais em períodos } \\
\text { inferiores a 30s e posturas estáticas por mais de } \\
1 \mathrm{~min} .\end{array}$ \\
\hline
\end{tabular}

Fonte: KLIEMANN; FERREIRA, 2010.

\subsubsection{Observação da atividade}

A observação da atividade revela aspectos do trabalho, na maioria das vezes, desconhecidos pelas empresas. A atividade em si, demonstra a grande variedade das atividades dos trabalhadores, 
para manter a produção em dia, além da pressão sofrida por eles para alcançar os objetivos, tais como a regulação de incidentes, a escolha de informações pertinentes, a antecipação e controle das ações, bem como os raciocínios apropriados para cada movimento.

Também, permite compreender uma atividade, por intermédio, dos gestos, dos esforços, das posturas, dos deslocamentos, da comunicação e dos manifestos dos trabalhadores (OLIVEIRA et al., 2008). A figura 04 registra a observação da atividade por sequência de panos de fachada leste.

Figura 04 - Execução de reboco externo na fachada Leste

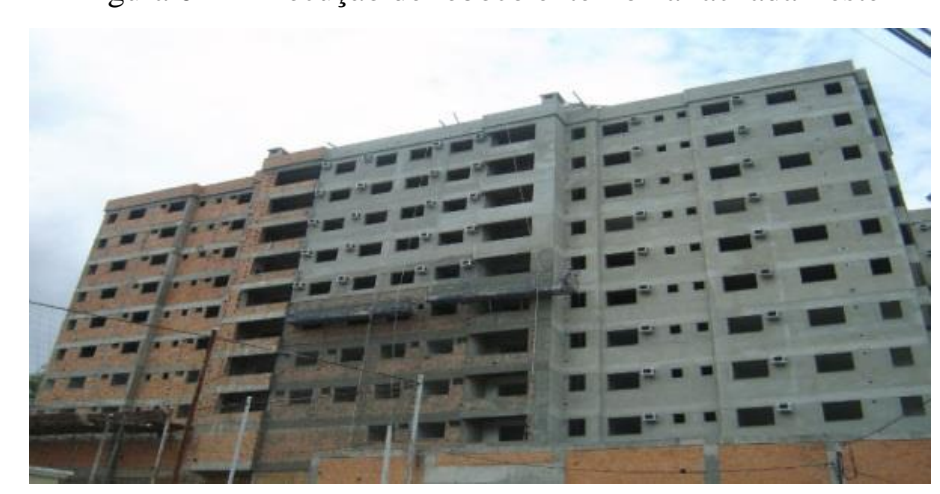

Fonte: Pesquisa de Campo (2015)

\subsubsection{Resultado dos Questionários Deparis}

Os resultados da aplicação prática da ferramenta de Diagnóstico preliminar Participativo de Risco (Deparis) com Engenheiros e Mestres de Obras foram resumidos no quadro 05.

Quadro 05: Resultados da aplicação prática da Ferramenta Deparis

\begin{tabular}{|c|c|c|c|}
\hline Rubrica & Respostas & $\begin{array}{l}\text { Avaliação } \\
\text { Gráfica }\end{array}$ & Ação \\
\hline \multirow{5}{*}{ Locais de Trabalho } & $\begin{array}{l}\text { Posto de Trabalho organizado, } \\
\text { porém necessita de mais } \\
\text { limpeza durante o dia. }\end{array}$ & & $\begin{array}{l}\text { Organizar as equipes de limpeza para } \\
\text { atuarem com maior frequência durante o } \\
\text { turno, para manter a frente de serviço limpa } \\
\text { durante o dia. }\end{array}$ \\
\hline & $\begin{array}{l}\text { Fácil acesso, pois os balancins } \\
\text { ao final do turno voltam ao } \\
\text { pavimento térreo. }\end{array}$ & & \\
\hline & $\begin{array}{l}\text { O trabalho no balancim não é } \\
\text { confortável, porém seguro, } \\
\text { possuindo espaço suficiente } \\
\text { para os movimentos. }\end{array}$ & 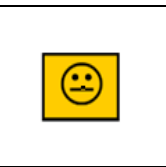 & $\begin{array}{l}\text { Substituição de equipamento por um modelo } \\
\text { seguro e que contemple as exigências da } \\
\text { Norma em vigor. }\end{array}$ \\
\hline & $\begin{array}{l}\text { O trabalho necessita de } \\
\text { posições como joelhos } \\
\text { agachados, torção de tronco e } \\
\text { braços elevados. }\end{array}$ & & $\begin{array}{l}\text { Instruir e treinar as equipes a usarem as } \\
\text { posições corretas para a execução do serviço, } \\
\text { incluindo períodos de descanso durante o } \\
\text { turno de trabalho. }\end{array}$ \\
\hline & $\begin{array}{l}\text { Os EPCs estão boas condições } \\
\text { de uso e suficientes para a } \\
\text { obra. }\end{array}$ & $(-)$ & \\
\hline Os Riscos de Acidentes & $\begin{array}{l}\text { Sim, estão expostos a quedas } \\
\text { de pessoas, objetos e fraturas. }\end{array}$ & & $\begin{array}{l}\text { Realizar a instalação dos EPCs e isolamento } \\
\text { de áreas necessárias para evitar a queda de } \\
\text { objetos e possíveis fraturas nas frentes de } \\
\text { serviço. }\end{array}$ \\
\hline
\end{tabular}




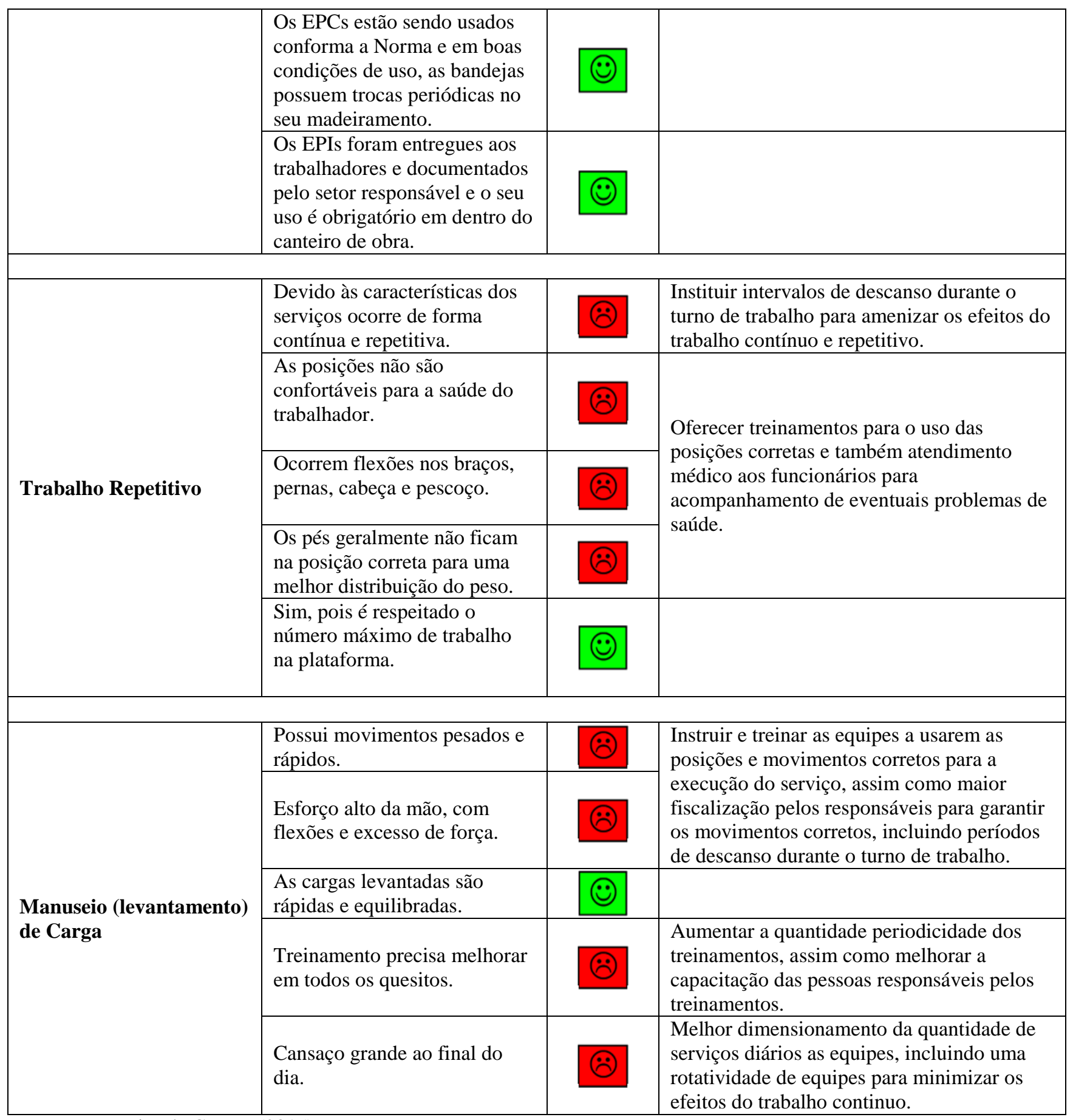

Fonte: Pesquisa de Campo (2015)

\section{Análise da Atividade}

Analisando as fotos da atividade de reboco externo na fachada da obra em questão bem como o resultado da ferramenta de diagnóstico Deparis, fica evidenciado uma falta de conecção entre o trabalho prescrito e a atividade desenvolvida. Os operários na frente de serviço para cumprir suas tarefas, infelizmente, adotam diversas posturas, que estão desacordo com as prescrições ergonômicas do trabalho e com as limitações do ser humano.

Nos postos de trabalho analisados, a atividade de se agachar e pegar a massa para aplicação na fachada ou a opção de usar o sistema de projeção em grandes áreas de reboco externo, exigem 
dos trabalhadores posturas inadequadas. Pode-se constatar também um dimensionamento errado em alguns andaimes, pois o uso da pá de pedreiro e do sistema de projeção de massa ocorre acima da linha dos ombros, assim como em algumas áreas da fachada, mesmo com o uso de balancim com uma extensão maior, encontra-se fora do alcance aceitável do operário. Outro problema a ser analisado é o tempo que os trabalhadores são obrigados a ficar por dia executando o serviço em seus postos de trabalho de forma contínua e com posturas erradas.

$\mathrm{Na}$ atividade de aplicação de argamassa o peso do corpo fica distribuído de forma desigual entre as pernas e os pés, fazendo com que ocorra o desenvolvimento de problemas relacionados a esta postura. Dentre eles podem-se citar dores na coluna, no pescoço e formigamento das pernas. Existe também uma falta de treinamento e informação dos trabalhadores em relação aos problemas ocasionados pelo desenvolvimento de atividades com constrangimentos posturais.

Não esquecendo também que em diversas situações a gravidade aumenta devido a posturas erradas dos trabalhadores para realizar algumas atividades.

Também foi observado que os operadores realizam um número maior de atividades em comparação com a prescrição inicial do serviço. Estas operações são "facilidades ou roubos" que os trabalhadores encontram na adaptação da atividade prescrita. Além do risco sempre iminente de queda devido ao perigo que a atividade possui.

\section{Conclusão}

A Construção Civil difere dos demais setores da indústria pela variabilidade das condições de trabalho e, consequentemente, dos constrangimentos a que os trabalhadores ficam submetidos. A execução de serviços externos em fachada de prédios, além dos riscos normais de um trabalho em altura, também apresenta os danos à saúde atribuídos ao setor da construção civil, como lesões na coluna e no pescoço e também em membros inferiores. Os resultados dos questionários com os profissionais que são responsáveis por essas atividades condizem com os encontrados em outros estudos já realizados neste campo, ou seja, apontando que as áreas do corpo afetadas nesse ramo a lombar e os joelhos em decorrência das posturas desfavoráveis e do manuseio de cargas excessivas.

O método elaborado permitiu a realização de um diagnóstico usando a ferramenta Deparis em situações ergonômicas envolvendo trabalho em altura em fachadas de obras prediais, a fim de verificar a situações dos trabalhadores envolvidos. Como já evidenciado na Análise da Atividade (item 04), o local de trabalho necessita de ajustes. Estes ajustes oscilam entre modificações de equipamentos, modificações na equipe num nível de intervenção de média complexidade e principalmente uma mudança de cultura nas empresas em geral. 
Para as empresas da Construção Civil, recomenda-se uma política de boas práticas de segurança do trabalho em altura, que consista na contratação de projetos arquitetônicos e complementares que valorizem métodos e processos construtivos voltados à segurança e saúde do trabalhador, a manutenção periódica dos equipamentos de proteção, em especial os usados para os serviços em altura nas fachadas, devido ao risco constante de queda e manutenção das proteções coletivas, procura por equipamentos mais leves e mais eficientes para execução do reboco externo, criação de um Programa de Atividades Executadas em Altura, baseada na NR - 35, com o objetivo de práticas treinamentos, uso correto dos EPCs e EPIs, palestra sobre as posturas a serem usadas em todos os tipos de atividades e treinamento em primeiro socorros e resgaste. Todas essas sugestões poderão influenciar num melhor desempenho na produção da obra e consequentemente uma melhoria na saúde dos trabalhadores.

\begin{abstract}
There are a number of situations involving risk of life in the Civil Construction and consequently ergonomic problems to the workers involved, generating a variability throughout the implementation process. Among all the risks known and studied in the Building Construction industry, the facade enforcement services are on the top of the list about terms of occupational accidents and ergonomic discomfort to workers' health. The NR-18 when it specifies the items to be followed by each work PCMAT, does not emphasize the security planning and health risks that workers are exposed. The challenge in ergonomic terms for this type of service is become a work area fully organized, with the use of appropriate tools, strictly respecting the rule, identification of the operators, the correct posture in raising the material and execution of the service, especially holding the check list in the work equipment height and conference of PPE. In order to determine the main risks to workers involved in this activity, an analysis by the preliminary diagnosis method Participatory risk (Deparis) was performed, resulting in the confirmation of the harmful nature of the activity because it has conditions that need immediate correction.
\end{abstract}

Key-words: ergonomics;façade;civil construction;deparis

\title{
Referências
}

ARAÚJO, N. M. C. de. Custos da Implantação do PCMAT na ponta do lápis. São Paulo: FUNDACENTRO, 2002.

BRASIL. 2012a.NR-18 - Condições e meio ambiente de trabalho na indústria da construção. Disponível em: <http://www.mte.gov.br/legislacao/normas_regulamentadoras/nr_18geral.pdf>. Acesso em: 18 abr. 2015.

BRASIL. 2012b. NR-35 - $\quad$ Trabalho em altura. Disponível em: <http://portal.mte.gov.br/data/files/8A7C816A3D63C1A0013DAB8EA3975DDA/NR-

$35 \% 20 \% 28$ Trabalho\%20em\%20Altura\%29.pdf>. Acesso em: 08 maio. 2015.

BRASIL. Ministério da Previdência Social Anuário estatístico de acidentes de trabalho. 2013. Disponível em: HTTP://www.previdenciasocial.gov.br/aeps2013/docs/3c30_05.xls. Acesso em: 03 maio 2015.

COSTELlA, M. F.; CREMONINI, R. A.; GUIMARÃES, L. B. Análise dos acidentes do trabalho ocorridos na atividade de construção civil no rio grande do sul em 1996 e 1997. IN: ENCONTRO NACIONAL DE ENGENHARIA DE PRODUÇÃO, 372, 1998, Niterói. Anais...Niterói : Universidade Federal Fluminense - UFF, 1998. Disponível em: <http://www.abepro.org.br/biblioteca/ENEGEP1998_ART372.pdf>. Acesso em: 06 maio. 2015. 
CRUZ, Sybele Maria Segala. Gestão de Segurança e Saúde Ocupacional nas Empresas de Construção Civil. 1998. 113f. Dissertação (Mestrado em Engenharia de Produção) - Programa de Pós-Graduação em Engenharia de Produção, Universidade Federal de Santa Catarina. Florianópolis/SC. 1998. Disponível em: <http://www.eps.ufsc.br/disserta99/sybele/>. Acesso em: 23 março. 2015.

ESPINOZA, J. W. M. Implementação de um programa de condições e meio ambiente no trabalho na indústria da construção para os canteiros de obras no subsetor de edificações utilizando um sistema informatizado. 2002. 107 f. Dissertação (Mestrado em Engenharia de Produção) - Programa de Pós-Graduação em Engenharia de Produção, Universidade Federal de Santa Catarina, Florianópolis.

KLIEMANN, M. P.; FERREIRA, M. S.Análise Ergonômica do Trabalho em Célula de Produção de Componentes Automotivos: Abordagem Top-Down e Bottom-up. Disponível em: http://revistaseletronicas.pucrs.br/ojs/index.php/graduacao/article/view/6755/4909. Acesso em: 04 julho. 2015.

KRUGER, J. A. ; COELHO, Clara Beatriz Trukes. Abordagens passadas e tendências futuras para o direcionamento da Ergonomia e da segurança do trabalho nos artigos publicados nos eventos da ANTAC. In: XI ENTAC - Encontro Nacional de Tecnologia no Ambiente Construído, 2006, Florianópolis. XI ENTAC - Encontro Nacional de Tecnologia no Ambiente Construído.

MALCHAIRE, J. Estrategia Geral de Gestão dos Riscos Profissionais SOBANE - Método de Diagnostico Preliminar Participativo dos Riscos. Universidade Católica de Louvain, Unidade de Higiene e Fisiologia do Trabalho. Bruxelas, 2003.

MANGAS, R. M. N. Acidentes fatais e a desproteção social na construção civil no Rio de Janeiro. 2003. 81p. Dissertação (Mestrado em Saúde Pública) - Fundação Oswaldo Cruz. Escola Nacional de Saúde Pública. Rio de Janeiro. 2003. Disponível em: <http://teses.icict.fiocruz.br/pdf/mangasrmnm.pdf>. Acesso em: 05 maio. 2015.

MARCONI, Marina de Andrade. LAKATOS, Eva Maria. Técnicas de pesquisa: planejamento e execução de pesquisa, amostragens e técnicas de pesquisa, elaboração, análise e interpretação de dados. $5^{\text {a }}$ Ed. São Paulo: Atlas, 2002, pg. ISBN 85-224-3263-5.

MPS. Menu de apoio - Estatísticas: Segurança e Saúde Ocupacional: Tabelas. 2014. Disponível em: <http://www.previdencia.gov.br/estatisticas/menu-de-apoio-estatisticas-seguranca-e-saude-ocupacional-tabelas/>. Acessado em: 03 maio. 2015.

OLIVEIRA, Silvio Luiz de. Tratado de metodologia científica: projetos de pesquisas, TGI, TCC, monografias, dissertações e teses. 2. ed. Revisão Maria Aparecida Bessana. São Paulo: Pioneira, 1997.

ORGANISME PROFESSIONNEL DE PRÉVENTION DU BÂTIMENT ET DES TRAVAUX PUBLIQUES Tecnologia de prevenção dos acidentes de trabalho na construção civil. Tradução e adaptação Fundação Centro Nacional de Segurança, Higiene e Medicina do Trabalho. São Paulo: FUNDACENTRO,1975.

PAMPALON, G.; FILHO, R. L.; VICENTE, L. F. Prevenção de acidentes do trabalho em serviços de manutenção em fachadas. 2. ed. São Paulo: SINTRACON, 2004. 14p. Disponível em: <http://sstmpe.fundacentro.gov.br/Anexo/Manual_de_Servicos_de_Manutencao_de_fachadas_Gianfranco.pdf >. Acesso em: 05 maio. 2015.

REVISTA COBERTURA. Acidente na construção sobe acima da média. São Paulo: Clipp-Seg produtos Cobertura Editora Ltda. 2010. Disponível em: //www.revistacobertura.com.br/lermais_materias.php?cd_materias=76046\&friurl=:Acidente-na-construcao-sobe-acima-da-media-:>. Acesso em: 05 maio. 2015.

ROCHA, C. A. G. S. de. Diagnóstico do cumprimento da NR - 18 no subsetor edificações da construção civil e sugestões para melhorias. 1999. 158 f. Dissertação (Mestrado em Engenharia) - Curso de Pós-Graduação em Engenharia Civil, Universidade Federal do Rio Grande do Sul, Porto Alegre.

ROCHA, C.A.; SAURIN, T.A.; FORMOSO, C.T. Avaliação da Aplicação da NR - 18 em canteiros de obras. In: ENCONTRO NACIONAL DE ENGENHARIA DE PRODUÇÃO, 2000, 10., São Paulo. Anais... Porto Alegre: UFRGS, 2000.

ROCHA, E. J. da. Avaliação de embargos e interdições na construção civil: estudo de caso em uma construtora e incorporadora de Porto Alegre. Porto Alegre, 2011. 92p. Monografia (Graduação em Engenharia Civil) Departamento de Engenharia Civil. Universidade Federal do rio Grande do Sul. Disponível em: <http://www.lume.ufrgs.br/bitstream/handle/10183/34398/000789681.pdf?sequence=1>. Acesso em: 29 abril 2015. 
SINDICATO DA INDÚSTRIA DA CONSTRUÇÃO DO ESTADO DO RIO GRANDE DO SUL. Cartilha de segurança no trabalho de andaimes. Publicação Técnica n. 02. Porto Alegre: SENAI, 1998

VÉRAS, J. C. Fatores de risco de acidentes do trabalho na indústria da construção civil: análise na fase de estruturas. 2004. 132f. Dissertação (Mestrado em Engenharia de Produção) - Programa de Pós-Graduação em Engenharia de Produção, Universidade Federal de Pernambuco - UFPE. Recife. 2004. Disponível em: <http://www.bdtd.ufpe.br/tedeSimplificado//tde_busca/arquivo.php?codArquivo=1239>. Acesso em: 05 maio. 2015.

\section{Dados dos autores:}

Nome completo: Juliano Prado Stradioto

Filiação Institucional: Universidade Federal do Rio Grande do Sul

Departamento: DEPROT - Departamento de Engenharia de Produção e Transporte

Função ou cargo ocupado: aluno de especialização

Endereço completo para correspondência: Rua Dr. Alcides Cruz, 100/apt 402, Bairro Santa Cecília, Porto Alegre, RS, CEP: 90.630-160.

Telefone para contato: (51) 97103666

e-mail: juliano.stradioto@gmail.com

\section{Nome Completo: Fernando Gonçalves Amaral}

Filiação Institucional: Universidade Federal do Rio Grande do Sul

Departamento: DEPROT - Departamento de Engenharia de Produção e Transporte

Função ou cargo ocupado: Professor Associado

Endereço completo para correspondência: Av. Osvaldo Aranha, 99 - $5^{\circ}$ andar, Bairro Centro, Porto Alegre, RS, CEP: 90.035-190

Telefone para contato: (51) 33084292

e-mail: amaral@producao.ufrgs.br 